Talía. Revista de estudios teatrales

ISSN-e 2659-806X

\title{
Simone Trecca, Filmicidad / Literariedad / Teatralidad: la diseminación intermedial de tres clásicos españoles. Madrid: Visor, 2019. ISBN: 978-84-9895-217-9. 178 pp.
}

Mario de la Torre Espinosa ${ }^{1 *}$

Las relaciones entre la literatura y el cine han sido múltiples y diversas desde la invención del cinematógrafo y tras la primera proyección en 1895. A diferencia de las primeras propuestas teóricas, que negaban la calidad artística del cinematógrafo, hoy día no cabe duda de que en realidad la atracción ha sido mutua. Además, las influencias de un medio sobre el otro han sido constantes, pero se debe reconocer que el cine se apropió en sus primeros momentos de técnicas narrativas y temas que la literatura ya había probado exitosamente.

Es evidente que aún persiste el prejuicio de que lo literario ocupa una posición jerárquicamente superior, lo que ha provocado que el resto de las artes se hayan subsumido a su dominio en numerosas ocasiones, algunas incluso siendo consideradas ancilares, como puede ser el caso del cine durante un amplio periodo. Es por ello que la monografía de la que nos ocupamos suponga un valioso intento de proponer alternativas que ayuden a romper con esta tendencia en los estudios literarios/ artísticos. Valga como ejemplo la refutación que lleva a cabo de conceptos como el de "fidelidad al texto originario" cuando nos hallamos ante procesos adaptativos, una interpretación que asumía la posición canonizada de lo literario como ente superior. Es su objetivo, en concreto, ofrecer otras vías que contribuyan a contemplar la valía de ciertos mitos literarios deslindándolos de apreciaciones basadas en el valor del medio. De esa manera pretende desvincularse del recelo que suele suscitar cualquier producto cultural que cuenta con un claro hipotexto literario.

Para ello, Simone Trecca, autor único de esta monografía, analiza cómo tres textos clásicos españoles integrantes del canon oficial han persistido a lo largo del tiempo. Se trata de El Lazarillo de Tormes, El Quijote y la obra dramática de Valle-Inclán, ejemplos literarios que tienen un amplio, aunque desigual, reconocimiento internacional. Su valía artística es la que se muestra como impulsora del desarrollo posterior de numerosas obras que expanden el universo ficcional de estas propuestas. Y aunque la labor de selección de las adaptaciones más significativas puede resultar dudosa a priori, el análisis que efectúa justifica sobradamente tanto su elección como el corpus resultante.
El autor comienza a desarrollar en un primer momento algunos conceptos presentes en el título de la obra y que generan cierta controversia por la pluralidad de sentidos que se le ha ido otorgando a lo largo del tiempo. Un ejemplo claro son las tensiones generadas cuando se ponen en relación con el concepto de canon, y cuando además Trecca lo aplica indiferentemente tanto a los autores como a las obras. Para explicar este fenómeno se vale de las teorías sistémicas, en concreto de la semiótica de la cultura de Yurij. M. Lotman y de la teoría de los polisistemas de Itamar Even-Zohar (algo que ya propondría muy acertadamente José María Pozuelo Yvancos). Se acerca así a las últimas tendencias en investigaciones literarias recientes, aunque al final opte por entender el concepto "clásico" como algo estático, en contra de lo que vendría siendo una perspectiva sistémica propiamente dicha.

Dentro de esta lógica sistémica, el autor trabaja con el concepto de reescritura de José Antonio Pérez Bowie, término que este ha ido desarrollando desde su Grupo de Estudios sobre Literatura y Cine (GELYC) de la Universidad de Salamanca. Pérez Bowie propone este concepto para rebatir con firmeza el concepto de fidelidad, ya que, al igual que consideraba Robert Stam, implica una jerarquización entre las artes del todo inoperativa y anacrónica. Trecca por tanto, a la hora de analizar los procesos a los que se han visto sometidos los textos clásicos, opta por emplear la noción de reescritura, cuya lógica es la siguiente: el texto 1, correspondiente al contexto 1, se convierte en un texto 2 modificando el texto 1 libremente y de acuerdo a las claves estilísticas y discursivas del sistema de llegada para hacerlo coincidir con el contexto 2.

A la hora de llevar a cabo la selección del corpus analizado, Trecca parte de la idea de "clásicos españoles", trascendiendo así, y gracias a este marchamo cultural, lo estrictamente literario. De esta forma, el autor procede a su análisis desde un punto de vista contenidista y sin dar gran importancia al medio originario de estos textos. Este desplazamiento del interés en su estudio está directamente conectado con su objetivo principal: analizar las reescrituras de los textos que se han ido produciendo una vez que han sido apropiados por autores o autoras y en diferentes medios. 
El primero de estos clásicos es La vida de Lazarillo de Tormes y de sus fortunas y adversidades. Entre los casos estudiados resulta muy llamativo el filme $E l$ Lazarillo de Tormes (1959), de César Fernández Ardavín, ya que el contexto nacionalcatólico de la dictadura franquista se hace presente a través del marco diegético que da lugar a la narración, en el que el protagonista se confiesa a un sacerdote en el prólogo y en el epílogo y se arrepiente de sus acciones.

Esta manera en la que se hace presente la moral de la época en el relato fílmico es uno de los fenómenos que más le interesan a Trecca, hasta el punto de haberle impelido a afrontar la escritura de la obra. Es precisamente a este respecto donde la obra alcanza su mayor interés, en indagar acerca de cómo la traslación de contenido entre diferentes medios se ve afectada por el contexto del sistema cultural de llegada. Es lo que se analiza también a colación de la película Don Quichotte, de Georg Wilhelm Pabst (1933), en concreto en los previos a la escena del ataque a los molinos. En esta parte del metraje el hidalgo caballero se encuentra con un grupo de obreros cargando con costales de harina y que son explotados por el Duque, al que deben rendir tributo y por quien tuvieron que vender incluso sus asnos. Vemos aquí otro ejemplo de reescritura donde se introduce el interés de Pabst por los temas sociales, preocupación que le acarrearía el exilio de la Alemania nazi, entre otros problemas.
Por último, el otro gran texto de la cultura española analizado es Divinas palabas y el esperpento valleinclanesco, en concreto a través de las obras recogidas en Martes de Carnaval. Lo dificultoso de su adaptación ya había sido trabajado ampliamente por José Antonio Pérez Bowie, pero Trecca aborda los casos estudiados aportando una nueva perspectiva donde pone de relieve las formas metateatrales y metafílmicas presentes en sus adaptaciones. La modernidad de los textos de Valle-Inclán es puesta de relieve gracias a una serie de estrategias narrativas que ponen en evidencia la riqueza de los personajes y mundos ficcionales creados por el autor español, y al mismo tiempo se potencia todo el carácter intermedial preinscrito en estas obras.

Con este último análisis se cierra una monografía que, desde el Hispanismo y el comparatismo intermedial, puede convertirse en un excelente material de trabajo para abordar todas las cuestiones señaladas, demostrando cómo "las ideas de literariedad, filmicidad y teatralidad se reestructuran (y reestructuran sus estrategias modelizantes) en el doble proceso productivo-receptivo entendido como práctica comunicativa reconocible y reconocida a nivel individual, colectivo e institucional, según las épocas" (Trecca, 2019, p. 28). Y, además, recurriendo a ejemplos canonizados de la cultura española que han tenido una amplia repercusión no solo en el ámbito hispanoamericano, sino en otros sistemas culturales. 